\title{
Effects of nitrogen-, boron-, and phosphorus-doping or codoping on metal-free graphene catalysis
}

\author{
Xiaoguang Duan, Stacey Indrawirawan, Hongqi Sun*, Shaobin Wang* \\ Department of Chemical Engineering, Curtin University, GPO Box U1987, WA 6845, \\ Australia \\ *Correspondence Authors. \\ Email: shaobin.wang@curtin.edu.au (S.Wang); h.sun@curtin.edu.au (H. Sun)
}

\begin{abstract}
Graphene-based materials have been demonstrated as excellent alternatives to traditional metal-based catalysts in environmental remediation. The metal-free nature of the nanocarbons can completely prevent toxic metal leaching and the associated secondary contamination. In this study, nitrogen doped graphene (NG) at a doping level of 6.54 at.\% was prepared at mild conditions. Moreover, B- and P-doping or codoping with $\mathrm{N}$ in graphene were also achieved by a simple route. The modified graphene can efficiently activate peroxymonosulfate (PMS) to produce sulfate radicals to oxidize phenol solutions. Kinetic studies indicated that initial phenol concentration, PMS dosage, and temperature presented significant influences on the degradation rates. Electron paramagnetic resonance (EPR) analysis provided further insights into the evolution of active radicals during the activation of PMS and $\mathrm{SO}_{4}{ }^{--}$was believed to be the primary radicals in the oxidation reactions. This study demonstrated a metal-free material for green catalysis in environmental remediation.
\end{abstract}

Keywords: Graphene; Sulfate radicals; Phenol; EPR; Nitrogen doping 


\section{Introduction}

Industrial processes have discharged a large amount of wastewater, in which hazardous components, such as phenolics, dyes, and pharmaceuticals, have posed great threats to the aquatic life, agriculture, and public health of human beings [1, 2]. Meanwhile, the lack of clean water resources occurs worldwide. Effective remediation technologies for removal of organic pollutants from wastewater for water reuse are therefore highly in demand. Advanced oxidation processes (AOPs) have drawn intensive attention, as they can completely decompose organics into water, carbon dioxide and inorganic ions/acids/groups by the active radicals [3-5]. Among various AOPs, Fenton reaction, based on a $\mathrm{H}_{2} \mathrm{O}_{2} / \mathrm{Fe}$ (II) homogeneous system, is mostly popular and has been widely applied due to the capability to destroy a wide range of contaminants [6]. However, Fenton reaction suffers from the drawbacks such as generation of excess sludge and low $\mathrm{pH}(\sim 3)$ requirement [7].

Recently, heterogeneous catalytic oxidation using peroxymonosulfate (PMS, commercially available as Oxone $^{\circledR}$ ) with cobalt catalysts has been employed for phenol oxidative decomposition [8-10]. Sulfate radicals $\left(\mathrm{SO}_{4}{ }^{{ }^{-}}\right)$produced from PMS are believed to possess a higher oxidation potential $(2.5 \sim 3.1 \mathrm{~V})$ than hydroxyl radicals $\left({ }^{\circ} \mathrm{OH}, 2.7 \mathrm{~V}\right)$, then they not only present better oxidation towards phenol degradation, but are flexible to a broad range of $\mathrm{pH}$ solutions [11]. However, cobalt leaching has inevitably occurred, giving rise to the secondary contamination to water body and bringing out other health issues to human beings [12].

The emerging nanocarbons, such as graphene, carbon nanotubes (CNTs), carbon nanofiber (CNF), and nanodiamond, as metal-free catalysts, have attracted considerable research interests and been applied to various catalytic processes [13-16]. The unique characteristics such as large specific surface area (SSA), super capability of electron transfer, good thermal stability, and non-toxicity also make them promising alternatives for environmental remediation $[17,18]$. Sun et al.[17], for the first time, reported that a reduced graphene oxide (rGO) through a hydrothermal approach can demonstrate an excellent performance in PMS activation and provide $70 \%$ phenol removal in $180 \mathrm{~min}$. Structural modification was found to be effective for improving the catalytic activity in phenol oxidation [19, 20]. It was well known that chemical doping could offer an effective method to modulate the electron states of graphene and bring about new properties [21]. Nitrogen doping was demonstrated to significantly improve the catalytic activities of nanocarbons for PMS activation [22, 23]. 
In this study, graphene oxide (GO) was synthesized by a modified Hummers method [24] and $\mathrm{N}$-doped graphene was prepared by annealing GO with ammonium nitrate as a $\mathrm{N}$ precursor in mild preparation conditions. The effects of $\mathrm{N}-, \mathrm{P}-$, and B-doping or codoping in $\mathrm{GO}$ on physicochemical properties of graphene were also investigated. The obtained catalysts were applied to activate PMS for catalytically oxidative removal of phenol in aqueous solutions. Kinetic studies and stability tests of the nanocarbons were systematically carried out. The degradation mechanism was also investigated and discussed.

\section{Experimental}

\subsection{Synthesis of nanocarbon catalysts}

Graphene oxide (GO) was synthesized by oxidation of natural graphite powders with condensed sulphuric acid and potassium permanganate reported elsewhere [24]. For synthesis of nitrogen doped materials, GO (1.0 g) was dispersed in ethanol $(50 \mathrm{~mL})$, stirred for $1 \mathrm{~h}$ and sonicated for $30 \mathrm{~min}$. Then ammonium nitrate $(1.0 \mathrm{~g})$ was added into the solution as the nitrogen precursor. The mixture was stirred and heated on a hotplate at $60{ }^{\circ} \mathrm{C}$ to evaporate ethanol. The dried mixture was finely grinded and transferred into a muffle furnace and calcined at $350{ }^{\circ} \mathrm{C}$ for $1 \mathrm{~h}$ and the resulted sample was denoted as NG350. For a comparison, an undoped rGO350 sample was prepared via GO thermal reduction at $350{ }^{\circ} \mathrm{C}$ in $\mathrm{N}_{2}$.

Additional boron and phosphorus doped graphene samples were synthesized following the same procedure of nitrogen-doped sample using certain amounts of ammonium pentaborate octhydrate $\left(\mathrm{H}_{8} \mathrm{~B}_{10} \mathrm{~N}_{2} \mathrm{O}_{16} \cdot 8 \mathrm{H}_{2} \mathrm{O}\right)$ and ammonium phosphate monobasic $\left(\mathrm{NH}_{4} \mathrm{H}_{2} \mathrm{PO}_{4}\right)$ as the boron $\left(\mathrm{B}_{2} \mathrm{O}_{3}\right)$, and phosphorus $\left(\mathrm{P}_{2} \mathrm{O}_{5}\right)$ precursors, respectively. The samples were denoted as B-rGO and P-rGO, respectively. To prepare B- (or P-) and $\mathrm{N}$ - co-doped graphene, the ammonium pentaborate octahydrate (or ammonium phosphate monobasic) and ammonium nitrate were added simultaneously into the GO suspension after sonication. The samples were referred as BNG and PNG, respectively.

\subsection{Characterization of nanocarbons}

Scanning electron microscopy (SEM, Zeiss Neon 40EsB FIBSEM) was performed to obtain the surface morphology of the catalysts. X-ray photoelectron spectroscopy (XPS, Thermal Escalab 250) was conducted with an $\mathrm{Al} \mathrm{K \alpha}$ source. X-ray diffraction (XRD) patterns were acquired from a Bruker D8-Advanecd X-ray diffractometer with $\mathrm{Cu}-\mathrm{K} \alpha$ radiation $(\lambda=1.5418$ 
$\AA ̊$ ). Raman spectra were conducted on an ISA dispersive Raman spectrometer. The BrunauerEmmett-Teller (BET) specific surface area, pore volume and pore distribution analyses were conducted on a Micrometrics Tristar 3000 in liquid nitrogen $\left(-196{ }^{\circ} \mathrm{C}\right)$ with the BET and Barrett-Joyner-Halenda (BJH) method. Fourier-transform infrared (FT-IR) spectra were obtained from a Perkin-Elmer Spectroscopy 100. Thermal analysis of nanocarbons was performed on a Mettler-Toledo Star system with thermal gravimetric analysis-differential scanning calorimetry (TGA-DSC) under air heating from 35 to $900{ }^{\circ} \mathrm{C}$ at a rate of $10{ }^{\circ} \mathrm{C} / \mathrm{min}$.

\subsection{Catalytic oxidation of phenol solutions}

Degradation reactions were carried out in a batch reactor containing $250 \mathrm{~mL}$ of phenol solution. Reaction temperature was kept at $25^{\circ} \mathrm{C}$ by a temperature controller set in a water bath. A certain amount of catalyst was added into the solution, which was mechanically stirred at a speed of $400 \mathrm{rpm}$ to form a well-mixed heterogeneous system before and after the addition of Oxone ${ }^{\circledR}\left(2 \mathrm{KHSO}_{5} \bullet \mathrm{KHSO}_{4} \bullet \mathrm{K}_{2} \mathrm{SO}_{4}\right.$, Sigma-Aldrich). During each interval time, 1 $\mathrm{mL}$ of the solution was withdrawn and filtered with $0.45 \mu \mathrm{m}$ membrane, and then injected into a HPLC vial mixed with $0.5 \mathrm{~mL}$ methanol as the quenching agent. The sample was analyzed by a High Performance Liquid Chromatography (HPLC) from Varian Instrument with a C18 column and a UV detector set at $270 \mathrm{~nm}$. Electron paramagnetic resonance (EPR) spectra were obtained on a Bruker EMS-plus equipment to identify and quantify the active radicals produced from PMS activation (centre field: $3516 \mathrm{G}$; sweep width: $100 \mathrm{G}$; microwave frequency: $9.87 \mathrm{GHz}$; power: $18.75 \mathrm{~mW}$ ).

\section{Results and discussion}

\subsection{Characterization of the materials}

Fig.1 displays SEM images of GO and modified rGO samples. GO was found to be of smooth, layered structure. After modification with heteroatoms (N, B, and P) via reduction, the layered graphene was further exfoliated and became obviously stacked layers compacted together at the edges. Similar structure was also observed on sulphur-doped rGO in other studies and the partially crinkled structure might be ascribed to the defective structure formed during the reduction and doping process via annealing at a moderate temperature $[25,26]$. 

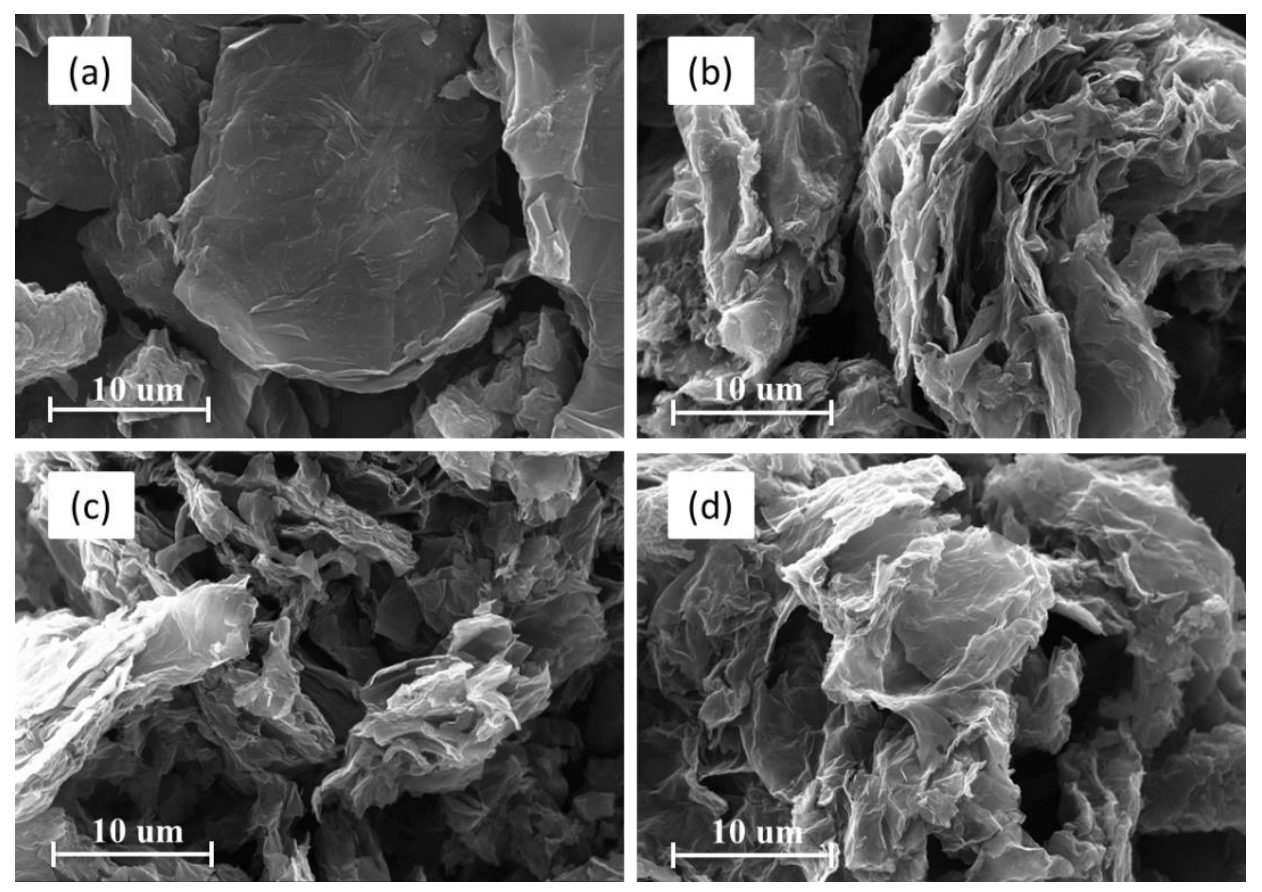

Fig. 1 SEM image of (a)GO, (b)NG350, (c)BNG 0.1\% $\mathrm{B}_{2} \mathrm{O}_{3}$, and (d)PNG 0.1\% $\mathrm{P}_{2} \mathrm{O}_{5}$.

XPS survey of NG350 from $0 \sim 1200 \mathrm{eV}$ was shown in Fig. 2(a). It was found that 6.54 at.\% nitrogen doping was achieved and 9.36 at.\% of oxygen still remained in graphene after the reduction annealing at $350{ }^{\circ} \mathrm{C}$. It was reported that the acidic surface oxides such as hydroxyl started to decompose at about $250{ }^{\circ} \mathrm{C}$, whereas the decomposition of carbonyl and phenol groups needed a higher temperature over $500{ }^{\circ} \mathrm{C}$ [27]. High-resolution of N1s spectrum was applied to reveal the chemical states of different types of $\mathrm{N}$ dopants. The weak peaks at the binding energy of $405.1 \mathrm{eV}$ and $401.8 \mathrm{eV}$ in Fig. 2(b) were assigned to the nitric oxide and quaternary $\mathrm{N}$ (also known as graphitic $\mathrm{N}$ ), respectively, while the peaks at $398.5 \mathrm{eV}$ and $400.0 \mathrm{eV}$ were corresponding to the pyridinic and pyrrolic $\mathrm{N}$, respectively. The ratio of graphitic $\mathrm{N}$ : pyrrolic $\mathrm{N}$ : pyridinic $\mathrm{N}$ was $1: 3.71: 4.38$. The low contents of quaternary $\mathrm{N}$ was due to the low annealing temperature. $\mathrm{Li}$ et al. [28] reported that higher temperature can induce more substantial doping of graphitic $\mathrm{N}$ into the graphene layer, whereas $\mathrm{C}-\mathrm{N}$ bonds would break up and nitrogen was removed when annealing temperature reaching over $900{ }^{\circ} \mathrm{C}$. 

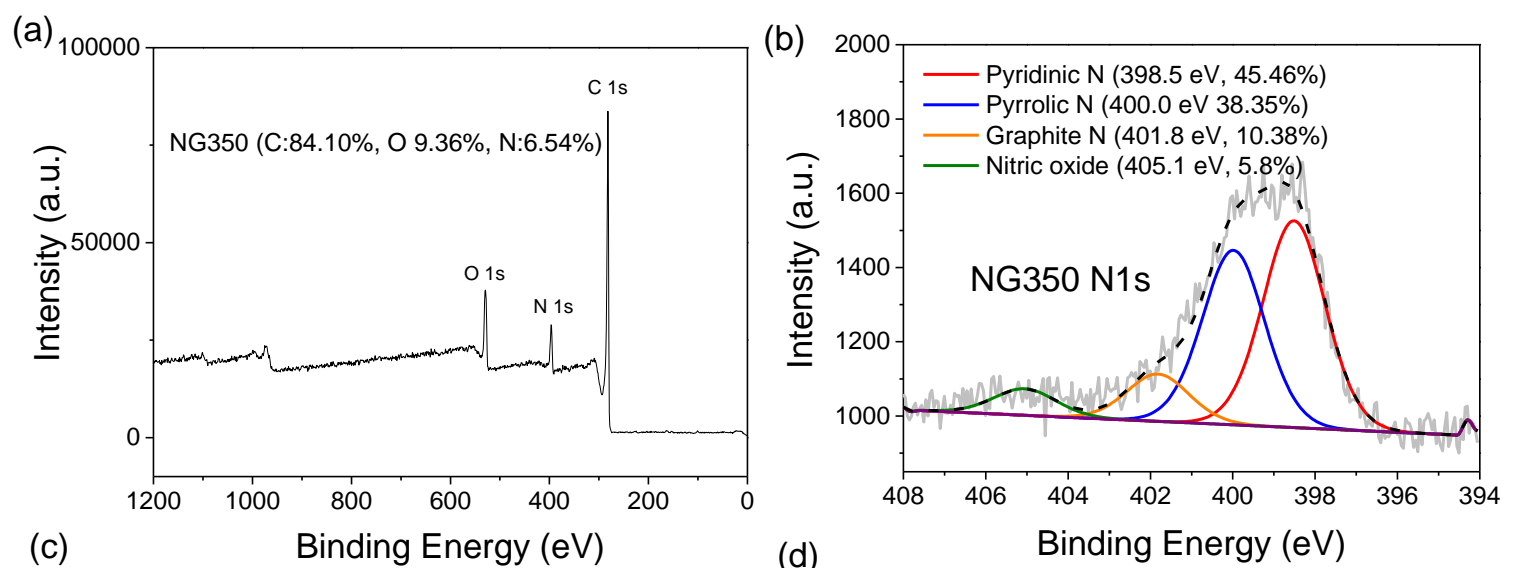

(c)

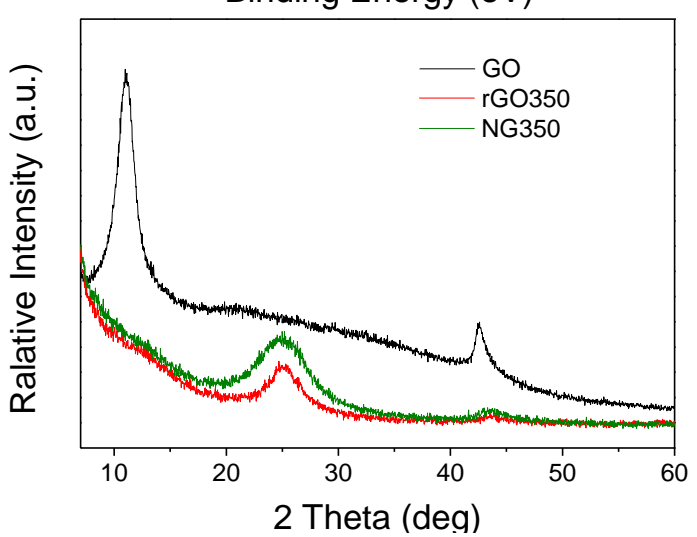

(d)

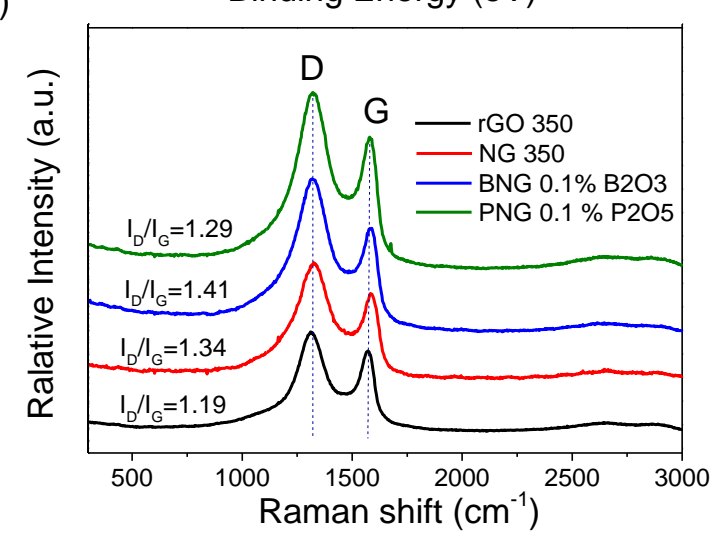

Fig. 2 (a) XPS survey, (b) XPS N1s of NG350, (c) XRD patterns of GO, rGO350, and NG350, and (d) Raman spectra of rGO, NG350, BNG and PNG.

Fig. 2(c) shows XRD patterns of GO, rGO350 and NG350. The sharp peak of GO at $11.0^{\circ}$ was assigned to the (002) graphite crystal with a c-axis interlayer space of $0.80 \mathrm{~nm}$. After annealing, the characteristic peak emerged at $21.6^{\circ}(0.41 \mathrm{~nm})$ indicates that most functional groups on the GO surface have been removed. Raman spectroscopy is a powerful and nondestructive technique to evaluate the number of layers, defects and degrees of disordered structures of carbon materials [29]. Fig. 2(d) compared the Raman shifts of rGO350, NG350, BNG, and PNG. The as-made catalysts present a common D band at $\sim 1320 \mathrm{~cm}^{-1}, \mathrm{G}$ band at $\sim 1580 \mathrm{~cm}^{-1}$, and a weak 2D band at $\sim 2660 \mathrm{~cm}^{-1}$. It is known that the $\mathrm{D}$ band is assigned to the vibrational mode induced by the disordered structure, whereas the $\mathrm{G}$ band and $2 \mathrm{D}$ band are corresponding to the $\mathrm{E}_{2 \mathrm{~g}}$ vibration of $\mathrm{sp}^{2}$-bonded graphitic carbon system [30]. The intensity ratio of $I_{D} / I_{G}$ is usually considered to present the degrees of defects. The $I_{\mathrm{D}} / I_{\mathrm{G}}$ values of NG350 (1.34), BNG (1.41) and PNG (1.29) are higher than rGO350 (1.19), indicating that the heteroatoms were successfully incorporated into the graphene planar layers and more defect sites were created by heteroatom doping. 
Fig. 3 shows the thermal analysis curves of the graphene-based materials. The quick weight loss of GO between 35 to $280{ }^{\circ} \mathrm{C}$ can be attributed to desorption of the adsorbed water and decomposition of oxygen groups on the surface of GO. After $500{ }^{\circ} \mathrm{C}$, the collapse of carbon skeleton occurs due to the combustion of carbon with air. Compared with the exothermic peak of rGO350 at 505 and $600{ }^{\circ} \mathrm{C}$, the peaks of NG350, BNG and PNG shifted to 749, 732 and $711^{\circ} \mathrm{C}$, respectively, suggesting that doping with heteroatoms can significantly enhance the thermal stability of graphene. It was reported that doping with boron or phosphorus could cover or block the combustion sites and depress the formation of $\mathrm{CO}_{\mathrm{x}}[31]$.
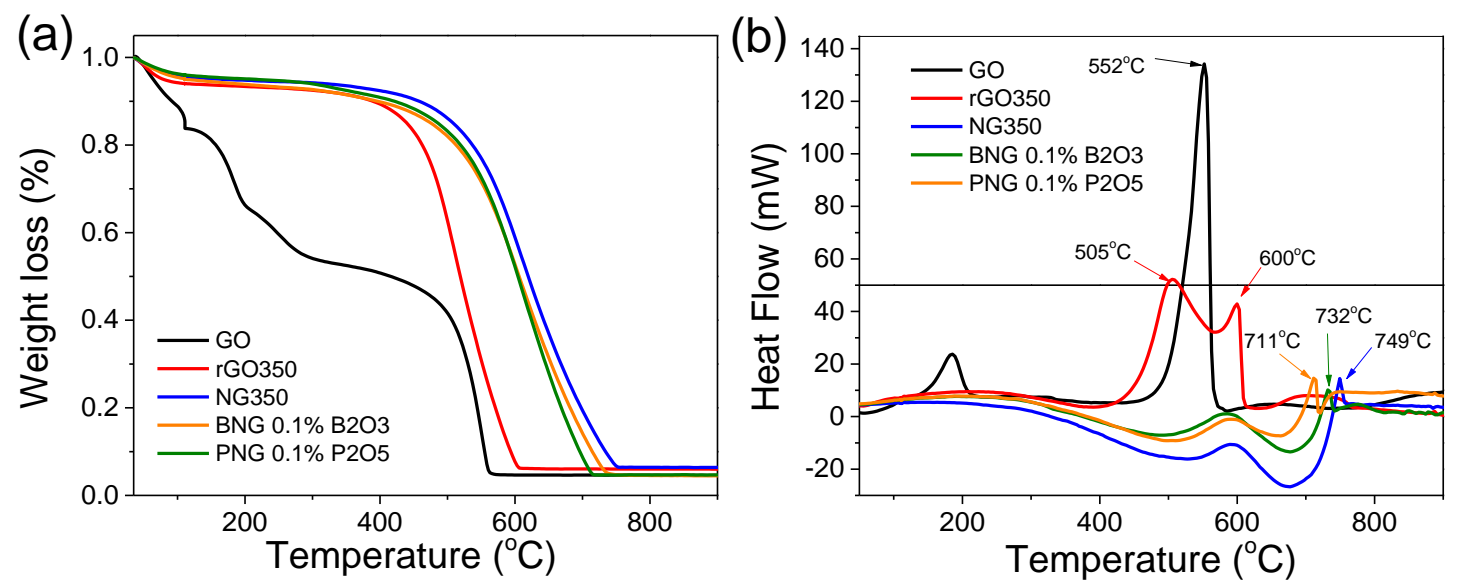

Fig. 3 TG and DSC profiles of nanocarbons.

Fig. 4 displays $\mathrm{N}_{2}$ sorption isotherms, pore size distributions, and specific surface areas (SSAs) of rGO and modified rGO. After nitrogen doping, $\mathrm{N}_{2}$ adsorption was decreased. Both micropores and mesopores were observed with pore sizes below $5 \mathrm{~nm}$ on rGO and NG350. Fig. 4(c) shows that, after modification with N, B and P, the SSA was significantly decreased from 255.4 (rGO350) to 71.5 (NG350), 71.4 (BNG), and $83.3 \mathrm{~m}^{2} / \mathrm{g}$ (PNG), possibly due to the crinkled layers formed from doping, as shown in the SEM images. Fig. 4(d) shows FT-IR spectra of the catalysts. The broad peak of GO at $2800 \sim 3700 \mathrm{~cm}^{-1}$ was corresponding to the water adsorption and $-\mathrm{O}-\mathrm{H}$ stretching, while the peaks at 1720 and $1580 \mathrm{~cm}^{-1}$ were assigned to the $-\mathrm{C}=\mathrm{O}$ and $-\mathrm{C}=\mathrm{C}$ stretching vibration, respectively. It can be seen that the oxygen groups were removed at some extents from the surface of graphene after annealing at $350{ }^{\circ} \mathrm{C}$. 

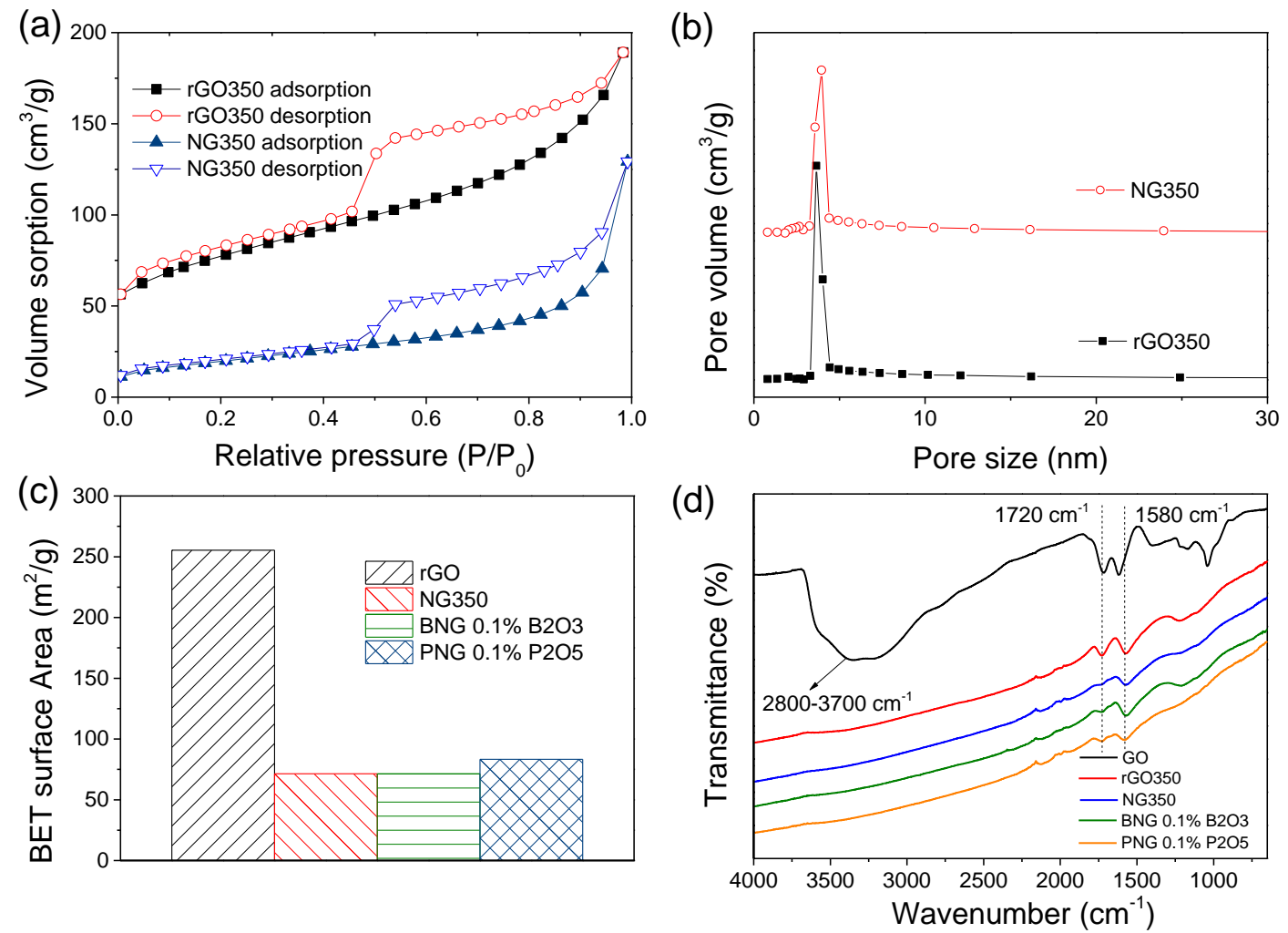

Fig. 4 (a) $\mathrm{N}_{2}$ sorption and (b) pore size distribution of rGO350 and NG350, (c) BET surface area of rGO350, NG350, BNG and PNG, and (d) FT-IR spectra of the carbon catalysts.

\subsection{Catalytic oxidation of phenol on nanocarbons}

Fig. 5 illustrates phenol oxidative decomposition under various conditions. GO showed a very low activity in activation of PMS. With consideration of XPS analysis showing no surface metal oxides, the contribution to phenol oxidation by any metal residuals in GO can be ruled out. After reduction, rGO350 showed a higher efficiency than GO. B- or P-doping was not able to significantly improve the activity of rGO. NG350 demonstrated the best performance for PMS activation with $85 \%$ phenol removal in $180 \mathrm{~min}$. When a pseudo first order reaction kinetics was applied (Eq. 1), the reaction rate constant of $\mathrm{N}$-doped graphene was almost 5.4-fold higher than the undoped rGO350. Interestingly, it was found that further co-doped $\mathrm{N}$ with $\mathrm{B}$ or $\mathrm{P}$ could not enhance the catalytic activity.

$$
C=C_{0} \exp (-k t)
$$




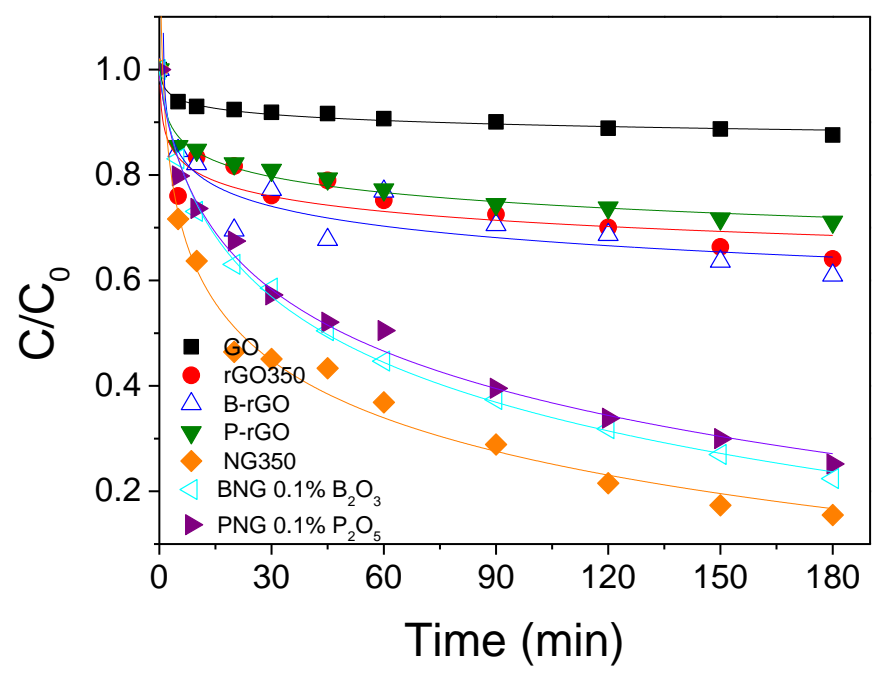

Fig. 5 Phenol degradation by activation of PMS over various nanocarbon catalysts. Reaction conditions: Catalyst $=0.2 \mathrm{~g} / \mathrm{L} ; \mathrm{PMS}=2 \mathrm{~g} / \mathrm{L} ;$ Phenol $=20 \mathrm{ppm}$; Temperature $=25^{\circ} \mathrm{C}$.

Fig. 6 reveals the effects of the codoped B or P levels on the phenol degradation rates. Fig. 6(a) shows that PMS could barely generate active radicals itself. Only 7.2, 7.4, and 9.1\% of phenol were removed by adsorption on NG350, BNG, and PNG, respectively. Fig. 6 (b) and (c) reveal that increasing the doping contents of boron or phosphorus could not increase the reaction rate. It was reported that both the electron-rich $(\mathrm{N})$ and electron-deficient (B) dopants could effectively activate the neighbouring $\mathrm{C}$ and break the electroneutrality of $\mathrm{sp}^{2}$ bonded carbon systems of graphene and create more charged sites for the oxygen reduction reaction (ORR) [32]. Both theoretical and experimental results illustrated that $\mathrm{B}$ and $\mathrm{N}$ bonded together in the same benzene ring could hardly break the inertness of CNT honeycomb carbon system and produced little catalytic ability toward ORR, due to the complementary effect between b- and p-type of dopants [33, 34]. It was suggested that decreased catalytic effect on phenol degradation after dual-doping (B-C-N or P-C-N) can be ascribed to the same reason. 

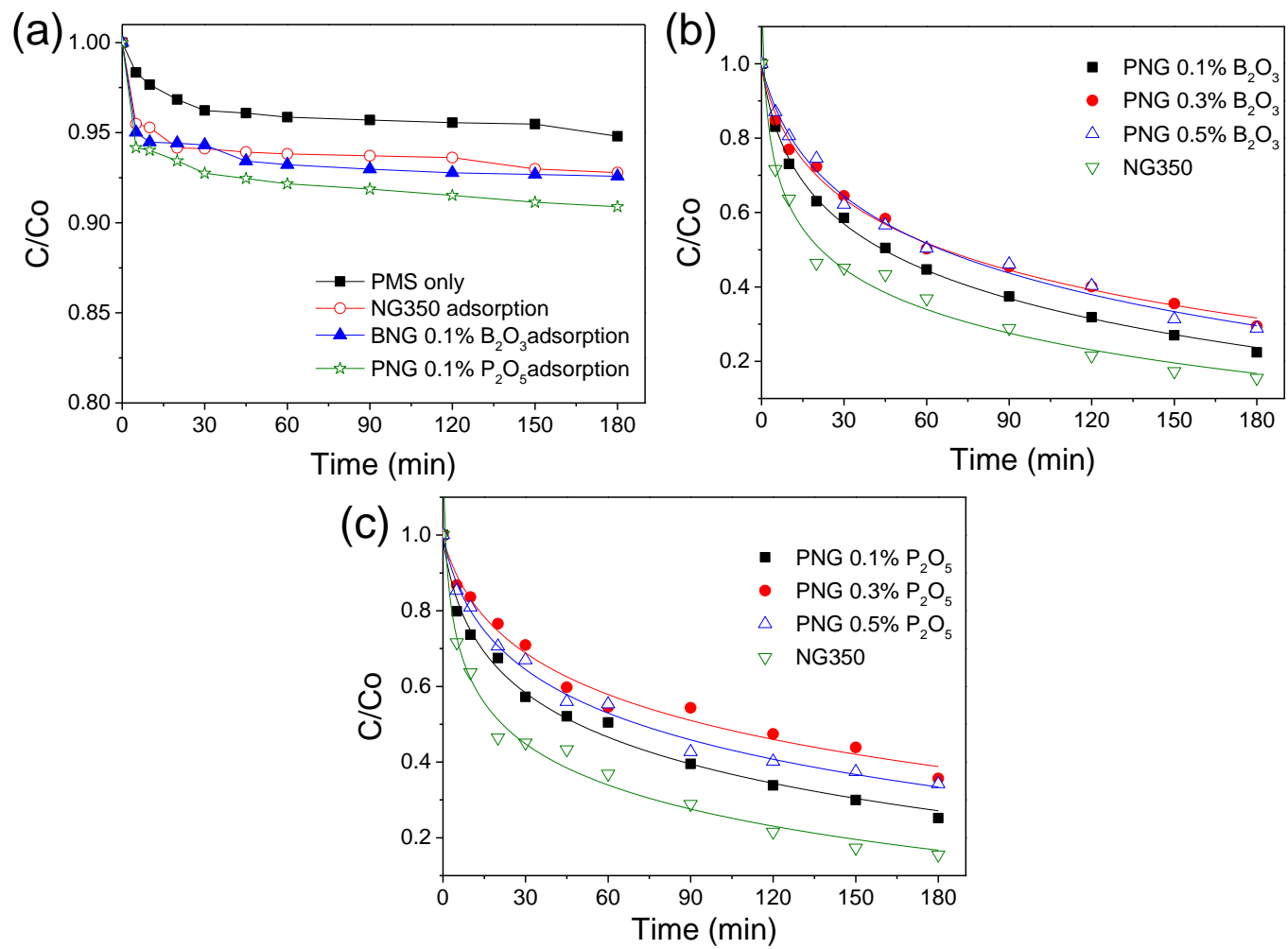

Fig. 6 (a) PMS self-activation and adsorption for phenol, and effect of co-doped B (b) and P (c) levels on phenol removal. Reaction conditions: Catalyst=0.2 g/L; PMS=2 g/L; Phenol=20 ppm; Temperature $=25^{\circ} \mathrm{C}$.

\subsection{Kinetic study of $\mathrm{N}$-doped graphene}

Further kinetic studies were carried out on the effect of operating conditions. The influence of initial phenol concentration on phenol removal is presented in Fig. 7(a, b). It was found that a higher initial phenol concentration leads to lower phenol degradation efficiency. More specifically, compared to $100 \%$ phenol removal achieved in 90 min in $10 \mathrm{ppm}$ phenol solution, only 85 and $37 \%$ of phenol were decomposed at concentrations of 20 and $50 \mathrm{ppm}$, respectively. The initial reaction rate constants estimated within the first $10 \mathrm{~min}$ before severe deactivation decreased from 0.071 (10 ppm) to 0.045 and $0.018 \mathrm{~min}^{-1}$ (20 and $50 \mathrm{ppm}$, respectively). In a higher phenol concentration solution, surface of the porous catalyst was quickly covered by the phenol and intermediates; therefore the contact of PMS with active sites was interfered. 

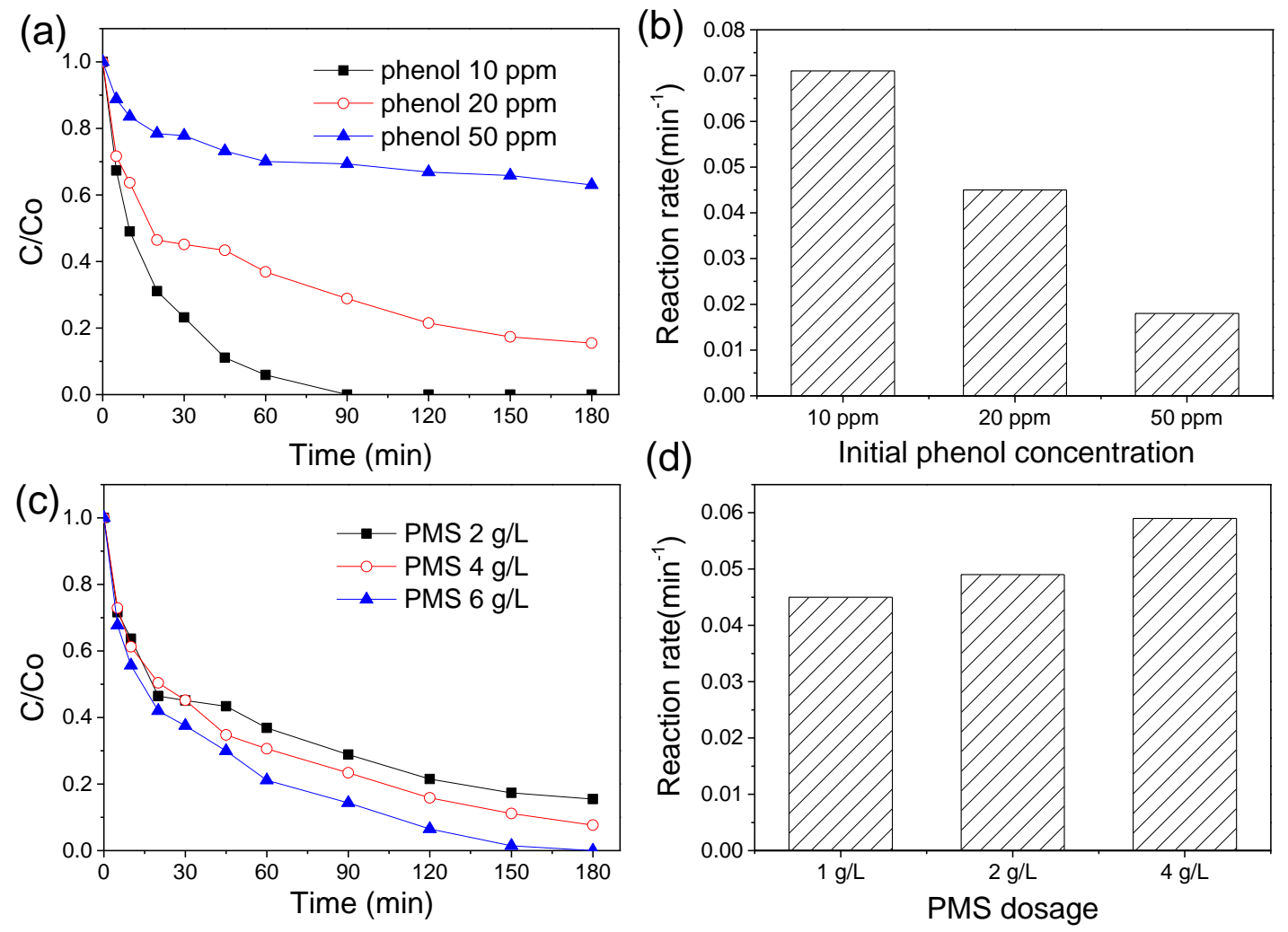

Fig. 7 Effects of initial phenol concentration $(a, b)$ and PMS dosage (c, d) on phenol removal.

Phenol removal efficiency was also affected by the oxidant dosage as shown in Fig. 7(c, d). Around 84.5, 92.4 and 100\% phenol removals were attained at the loading of 2.0, 4.0 and 6.0 $\mathrm{g} / \mathrm{L}$ of PMS, respectively, and the reaction rate constants were evaluated to be $0.045,0.049$, and $0.059 \mathrm{~min}^{-1}$, accordingly. The addition of PMS could bring about more active radicals and then enhance the reaction rate of phenol degradation.

In addition, temperature is also considered to be a crucial factor for determining the catalytic activity. Fig. 8(a) demonstrates the influence of temperature on phenol degradation. It is noted that elevated temperature gave rise to a higher phenol removal. For instance, $71.1 \%$ and $75.4 \%$ of phenol were removed at 25 and $35{ }^{\circ} \mathrm{C}$, respectively, in $120 \mathrm{~min}$, whereas $86.3 \%$ of phenol was degraded when reaction temperature was increased to $45{ }^{\circ} \mathrm{C}$. Based on the Arrhenius equation, apparent activation energy of the NG350/PMS in oxidative degradation of phenol was estimated to be $19.7 \mathrm{~kJ} / \mathrm{mol}$. This was much lower than that of some other nanocarbons and supported cobalt or manganese catalysts shown in Table 1. 

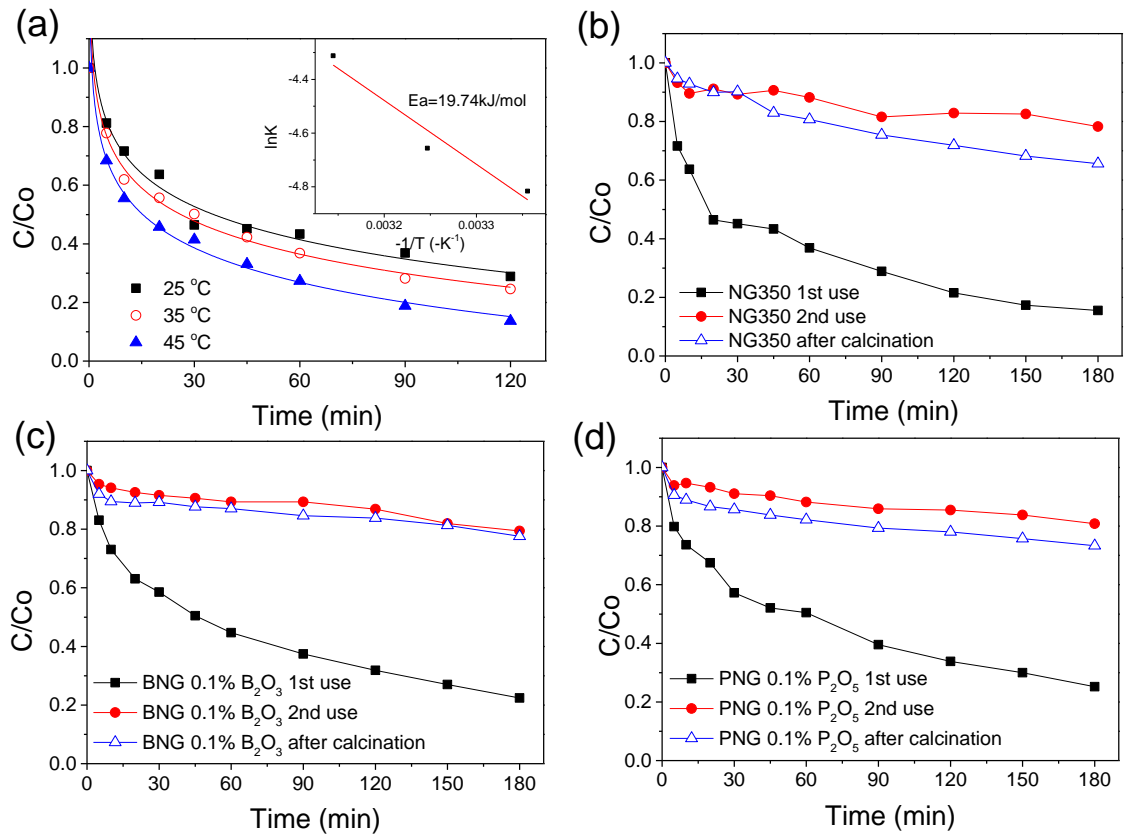

Fig. 8 (a) Temperature effect and activation energy of NG350 on phenol oxidation. Stability and recyclability tests of NG350 (b), BNG (c) and PNG (d).

Table 1 Comparison of activation energy of nanocarbon- and metal-based catalysts.

\begin{tabular}{lll}
\hline Catalysts & $\begin{array}{l}\text { Activation Energy } \\
(\mathrm{kJ} / \mathrm{mol})\end{array}$ & References \\
\hline Graphene & 84.0 & {$[17]$} \\
$\mathrm{N}-\mathrm{CNT}$ & 39.2 & {$[22]$} \\
$\mathrm{Co} / \mathrm{ZSM}-5$ & 69.7 & {$[11]$} \\
$\mathrm{Mn}_{3} \mathrm{O}_{4} / \mathrm{rGO}$ & 39.2 & {$[3]$} \\
$\mathrm{NG} 350$ & 19.7 & This study \\
\hline
\end{tabular}

The stability tests of doped nanocarbons were illustrated in Fig. 8(b, c, d). It was found that the catalytic performance of the catalysts dropped dramatically after the first use, due to the coverage of intermediates on the active sites on graphene surface. XPS and BET analyses (not shown here) of the spent catalyst also observed the structural and compositional changes after the reaction. After heat treatment in the air, only part of the catalytic activity was regenerated. The reusability of graphene could not be comparable with those metal catalysts reported in other studies $[3,35]$. The poor reusability of nanocarbons might be attributed to the reconstruction of dopants, structural changes and the strong interaction of the adsorbed 
phenol and intermediates, such as benzoquinone, maleic acid etc., with the graphene $\mathrm{sp}^{2}$ hybridized carbon network [36].

\subsection{Role of $\mathrm{N}$-doped graphene in PMS activation}

In our recent studies, it was found that $\mathrm{sp}^{2}$ carbon can facilitate the free flowing electrons transferred from the graphene basal layer to the oxidant for PMS activation [17]. In addition, the zigzag structure of graphene and minor quantity of rich-electron containing oxygen groups $(-\mathrm{C}=\mathrm{O})$ at the edges are believed to present further potential for the oxidation process of phenol degradation [31, 37]. In a sequent study, $\mathrm{N}$-modified multi-walled carbon nanotubes (N-MWCNT) demonstrated 7.8 folds of enhancement in reaction rate as compared to pristine MWCNTs and the nitrogen dopants were proposed to play a more crucial role than the oxygen groups for PMS activation [22].

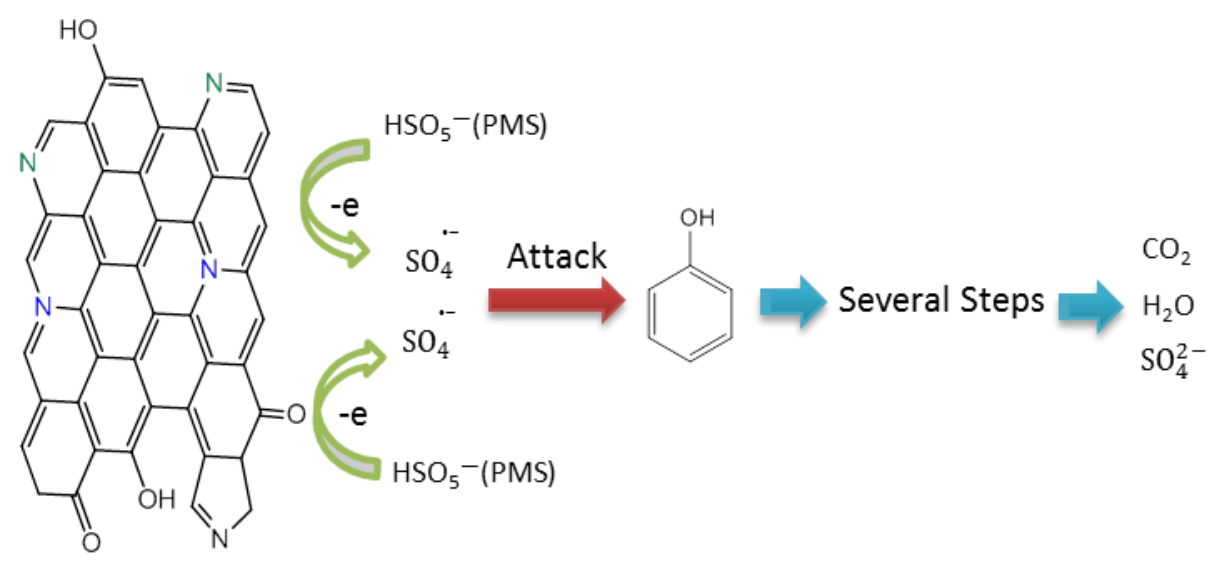

Scheme 1 PMS activation on N-doped graphene and the phenol oxidation process.

Electron paramagnetic resonance (EPR) was applied to investigate the evolution of active radicals generated during the reaction and 5,5-dimethylpyrroline-oxide (DMPO) was utilized as the spin trapping agent for quantitative analysis of the radicals. The sharp peaks in Fig. 9(a) suggested that the N-doped graphene can effectively activate PMS whereas the PMS itself could not generate lots of radicals itself, consistent with phenol oxidative degradation experiments. The DMPO radical adducts could be recognized by hyperfine splitting constants (DMPO-OH: $a_{N}=14.9 G, a_{H}=14.9$ G; DMPO-SO ${ }_{4}: a_{N}=13.2 \mathrm{G}, a_{H}=9.6 \mathrm{G}, a_{H}=1.48 G, a_{H}=0.78$ G) and the quantitative information was calculated by the Bruker Xenon software. 

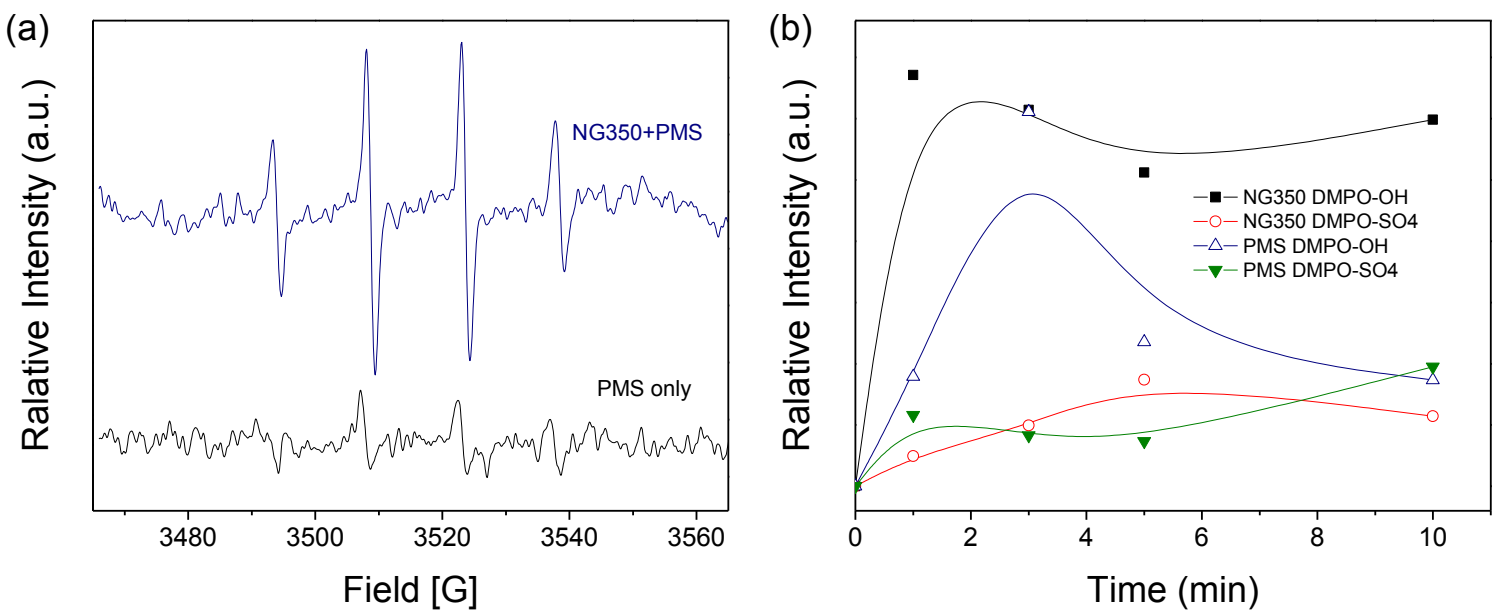

Fig. 9 (a) EPR spectra under different conditions, (b) Evolution of DMPO-OH and DMPO$\mathrm{SO}_{4}$ during the oxidation process.

Fig. 9(b) illustrates the variations of sulfate and hydroxyl radicals. It is noted that both ${ }^{\circ} \mathrm{OH}$ and $\mathrm{SO}_{4}{ }^{-}$were detected during the catalytic reaction. The intensity for DMPO-OH grew quickly in the first 1 minute, then slowly went down afterwards, suggesting that ${ }^{\circ} \mathrm{OH}$ was initially produced from the activation of PMS on NG350. The same trend was also found in the ACFs-CoPc/PMS system [38]. The relative weak intensity of DMPO-SO 4 was possibly due to the great consumption of $\mathrm{SO}_{4}{ }^{--}$for oxidation of phenol in the phenol aqueous solution. A handful study has indicated that $\mathrm{SO}_{4}{ }^{-}$, with a higher oxidative potential (2.5 3.1 eV vs 1.1 $\mathrm{eV}$ and $2.7 \mathrm{eV}$ of $\mathrm{SO}_{5}{ }^{-}$and ${ }^{\circ} \mathrm{OH}$ ), led a principle role in the oxidative decomposition of organic pollutants $[8,11,17,39]$. The possible reaction routes of the PMS activation on Ndoped graphene were proposed as below:

$$
\begin{aligned}
\mathrm{HSO}_{5}^{-}+e^{-} & \rightarrow \mathrm{OH}+\mathrm{SO}_{4}^{2-} \\
\mathrm{HSO}_{5}^{-}+e^{-} & \rightarrow \mathrm{SO}_{4}^{\cdot-}+\mathrm{OH}^{-} \\
\cdot \mathrm{OH}+\mathrm{SO}_{4}^{2-} & \rightarrow \mathrm{SO}_{4}^{\cdot-}+\mathrm{OH}^{-} \\
\mathrm{SO}_{4}^{--}+\mathrm{OH}^{-} & \rightarrow \mathrm{SO}_{4}^{2-}+\mathrm{OH}^{-} \\
\cdot \mathrm{OH}+e^{-} & \rightarrow \mathrm{OH}^{-} \\
\mathrm{SO}_{4}^{\cdot-}+e^{-} & \rightarrow \mathrm{SO}_{4}^{2-} \\
2 \mathrm{HSO}_{5}^{-}+2 \cdot \mathrm{OH} & \rightarrow 2 \mathrm{SO}_{4}^{--}+2 \mathrm{H}_{2} \mathrm{O}+\mathrm{O}_{2}
\end{aligned}
$$




$$
\begin{gathered}
\cdot \mathrm{OH}+{ }^{\cdot} \mathrm{OH} \rightarrow \mathrm{H}_{2} \mathrm{O}_{2} \\
\mathrm{SO}_{4}^{\cdot-}+{ }^{\cdot} \mathrm{OH} \rightarrow \mathrm{HSO}_{5}^{-} \\
\text {Phenol }+\mathrm{SO}_{4}^{--} \rightarrow \text { several steps } \rightarrow \mathrm{CO}_{2}+\mathrm{H}_{2} \mathrm{O}+\mathrm{SO}_{4}^{2-}
\end{gathered}
$$

\section{Conclusions}

The nitrogen doped graphene was synthesized by annealing graphene oxide with ammonium nitrate at a facile condition. A 6.54 at.\% of $\mathrm{N}$-doping level was achieved. The reaction rate of NG350 is about 5.4 folds of the undoped graphene in degradation of phenol with sulfate radicals. It is found that simultaneous co-doping of $\mathrm{N}$ with $\mathrm{B}$ or $\mathrm{P}$ could not enhance the catalytic efficiency. The kinetic studies indicated that initial concentration of phenol solution, PMS dosage, and temperature presented significant influences on phenol oxidative removal. The stability results showed that the catalytic activity of nanocarbons declined after the first use and part of the activity was recovered after heat treatment. EPR results gave a further insight into the evolution of active radicals during the reaction and $\mathrm{SO}_{4}{ }^{--}$was believed to the primary radicals in the oxidation reaction. This study proposed a facile method to enhance the catalytic activity of graphene for PMS activation and provided a metal-free material for green catalysis in environmental remediation.

\section{Acknowledgements}

This work was financially supported by Australian Research Council (DP130101319). The authors acknowledge the use of equipment, scientific and technical assistance of the Curtin University Electron Microscope Facility which has been partially funded by the University,

State and Commonwealth Governments. H. S. thanks the support from Curtin Research Fellowship.

\section{References}

[1] P. Shukla, H.Q. Sun, S.B. Wang, H.M. Ang, M.O. Tade, Co-SBA-15 for heterogeneous oxidation of phenol with sulfate radical for wastewater treatment, Cataly. Today, 175 (2011) 380-385.

[2] V.K. Gupta, I. Ali, T.A. Saleh, A. Nayak, S. Agarwal, Chemical treatment technologies for waste-water recycling-an overview, RSC Adv., 2 (2012) 6380-6388. 
[3] Y.J. Yao, C. Xu, S.M. Yu, D.W. Zhang, S.B. Wang, Facile synthesis of $\mathrm{Mn}_{3} \mathrm{O}_{4}$-reduced graphene oxide hybrids for catalytic decomposition of aqueous organics, Ind. Eng. Chem. Res., 52 (2013) 3637-3645.

[4] P.R. Shukla, S.B. Wang, H.Q. Sun, H.M. Ang, M. Tade, Activated carbon supported cobalt catalysts for advanced oxidation of organic contaminants in aqueous solution, Appl. Catal. B, 100 (2010) 529-534.

[5] M. Pera-Titus, V. Garcia-Molina, M.A. Banos, J. Gimenez, S. Esplugas, Degradation of chlorophenols by means of advanced oxidation processes: a general review, Appl. Catal. B, 47 (2004) 219-256.

[6] H.Q. Sun, H.Y. Tian, Y. Hardjono, C.E. Buckley, S.B. Wang, Preparation of cobalt/carbon-xerogel for heterogeneous oxidation of phenol, Catal. Today, 186 (2012) 63-68.

[7] S.K. Ling, S.B. Wang, Y.L. Peng, Oxidative degradation of dyes in water using $\mathrm{Co}^{2+} / \mathrm{H}_{2} \mathrm{O}_{2}$ and $\mathrm{Co}^{2+} /$ peroxymonosulfate, J. Hazard. Mater., 178 (2010) 385-389.

[8] H.Q. Sun, H.W. Liang, G.L. Zhou, S.B. Wang, Supported cobalt catalysts by one-pot aqueous combustion synthesis for catalytic phenol degradation, J. Colloid Interface Sci., 394 (2013) 394-400.

[9] H.W. Liang, H.Q. Sun, A. Patel, P. Shukla, Z.H. Zhu, S.B. Wang, Excellent performance of mesoporous $\mathrm{Co}_{3} \mathrm{O}_{4} / \mathrm{MnO}_{2}$ nanoparticles in heterogeneous activation of peroxymonosulfate for phenol degradation in aqueous solutions, Appl. Catal. B, 127 (2012) 330-335.

[10] Y.J. Yao, C. Xu, J.C. Qin, F.Y. Wei, M.N. Rao, S.B. Wang, Synthesis of magnetic cobalt nanoparticles anchored on graphene nanosheets and catalytic fecomposition of orange II, Ind. Eng. Chem. Res., 52 (2013) 17341-17350.

[11] P. Shukla, S.B. Wang, K. Singh, H.M. Ang, M.O. Tade, Cobalt exchanged zeolites for heterogeneous catalytic oxidation of phenol in the presence of peroxymonosulphate, Appl. Catal. B, 99 (2010) 163-169.

[12] Y.X. Wang, H.Q. Sun, H.M. Ang, M.O. Tade, S.B. Wang, Magnetic $\mathrm{Fe}_{3} \mathrm{O}_{4} /$ carbon sphere/cobalt composites for catalytic oxidation of phenol solutions with sulfate radicals, Chem. Eng. J., 245 (2014) 1-9.

[13] A.K. Geim, K.S. Novoselov, The rise of graphene, Nature Mater., 6 (2007) 183-191.

[14] B. Frank, M. Morassutto, R. Schomacker, R. Schlogl, D.S. Su, Oxidative dehydrogenation of ethane over multiwalled carbon nanotubes, ChemCatChem, 2 (2010) 644-648. 
[15] S. Maldonado, K.J. Stevenson, Influence of nitrogen doping on oxygen reduction electrocatalysis at carbon nanofiber electrodes, J. Phys. Chem. B, 109 (2005) 4707-4716.

[16] A. Krueger, New carbon materials: Biological applications of functionalized nanodiamond materials, Chem. Europ. J., 14 (2008) 1382-1390.

[17] H.Q. Sun, S.Z. Liu, G.L. Zhou, H.M. Ang, M.O. Tade, S.B. Wang, Reduced graphene oxide for catalytic oxidation of aqueous organic pollutants, ACS Appl. Mater. Interfaces, 4 (2012) 5466-5471.

[18] S.B. Wang, H.Q. Sun, H.M. Ang, M.O. Tade, Adsorptive remediation of environmental pollutants using novel graphene-based nanomaterials, Chem. Eng. J., 226 (2013) 336347.

[19] S.Z. Liu, W.C. Peng, H.Q. Sun, S.B. Wang, Physical and chemical activation of reduced graphene oxide for enhanced adsorption and catalytic oxidation, Nanoscale, 6 (2014) 766-771.

[20] W.C. Peng, S.Z. Liu, H.Q. Sun, Y.J. Yao, L.J. Zhi, S.B. Wang, Synthesis of porous reduced graphene oxide as metal-free carbon for adsorption and catalytic oxidation of organics in water, J. Mater. Chem. A, 1 (2013) 5854-5859.

[21] H.T. Liu, Y.Q. Liu, D.B. Zhu, Chemical doping of graphene, J. Mater. Chem., 21 (2011) 3335-3345.

[22] H.Q. Sun, C. Kwan, A. Suvorova, H.M. Ang, M.O. Tade, S.B. Wang, Catalytic oxidation of organic pollutants on pristine and surface nitrogen-modified carbon nanotubes with sulfate radicals, Appl. Catal. B, 154 (2014) 134-141.

[23] H.Q. Sun, Y.X. Wang, S.Z. Liu, L. Ge, L. Wang, Z.H. Zhu, S.B. Wang, Facile synthesis of nitrogen doped reduced graphene oxide as a superior metal-free catalyst for oxidation, Chem. Commun., 49 (2013) 9914-9916.

[24] W.S. Hummers Jr, R.E. Offeman, Preparation of graphitic oxide, J. Am. Chem. Soc., 80 (1958) 1339-1339.

[25] S.B. Yang, L.J. Zhi, K. Tang, X.L. Feng, J. Maier, K. Mullen, Efficient synthesis of heteroatom (N or $\mathrm{S}$ )-doped graphene based on ultrathin graphene oxide-porous silica sheets for oxygen reduction reactions, Adv. Funct. Mater., 22 (2012) 3634-3640.

[26] Y.Z. Su, Y. Zhang, X.D. Zhuang, S. Li, D.Q. Wu, F. Zhang, X.L. Feng, Lowtemperature synthesis of nitrogen/sulfur co-doped three-dimensional graphene frameworks as efficient metal-free electrocatalyst for oxygen reduction reaction, Carbon, 62 (2013) 296-301. 
[27] K. Kinoshita, Carbon: electrochemical and physicochemical properties, A WileyInterscience publication, 1988.

[28] X.L. Li, H.L. Wang, J.T. Robinson, H. Sanchez, G. Diankov, H.J. Dai, Simultaneous nitrogen doping and reduction of graphene oxide, J. Am. Chem. Soc., 131 (2009) 1593915944.

[29] A. Das, S. Pisana, B. Chakraborty, S. Piscanec, S.K. Saha, U.V. Waghmare, K.S. Novoselov, H.R. Krishnamurthy, A.K. Geim, A.C. Ferrari, A.K. Sood, Monitoring dopants by Raman scattering in an electrochemically top-gated graphene transistor, Nature Nanotechnol., 3 (2008) 210-215.

[30] J.L. Long, X.Q. Xie, J. Xu, Q. Gu, L.M. Chen, X.X. Wang, Nitrogen-doped graphene nanosheets as metal-free catalysts for aerobic selective oxidation of benzylica alcohols, ACS Catal., 2 (2012) 622-631.

[31] B. Frank, J. Zhang, R. Blume, R. Schlogl, D.S. Su, Heteroatoms increase the selectivity in oxidative dehydrogenation reactions on nanocarbons, Angew. Chem. Int. Ed., 48 (2009) 6913-6917.

[32] L.J. Yang, S.J. Jiang, Y. Zhao, L. Zhu, S. Chen, X.Z. Wang, Q. Wu, J. Ma, Y.W. Ma, Z. $\mathrm{Hu}$, Boron-doped carbon nanotubes as metal-free electrocatalysts for the oxygen reduction reaction, Angew. Chem. Int. Ed., 50 (2011) 7132-7135.

[33] Y. Zhao, L.J. Yang, S. Chen, X.Z. Wang, Y.W. Ma, Q. Wu, Y.F. Jiang, W.J. Qian, Z. $\mathrm{Hu}$, Can boron and nitrogen co-doping improve oxygen reduction reaction activity of carbon nanotubes? J. Am. Chem. Soc., 135 (2013) 1201-1204.

[34] M. Grundmann, The physics of semiconductors: An introduction including nanophysics and applications, Springer, 2010.

[35] E. Saputra, S. Muhammad, H.Q. Sun, H.M. Ang, M.O. Tade, S.B. Wang, Shapecontrolled activation of peroxymonosulfate by single crystal alpha- $\mathrm{Mn}_{2} \mathrm{O}_{3}$ for catalytic phenol degradation in aqueous solution, Appl. Catal. B, 154 (2014) 246-251.

[36] T. Olmez-Hanci, I. Arslan-Alaton, Comparison of sulfate and hydroxyl radical based advanced oxidation of phenol, Chem. Eng. J., 224 (2013) 10-16.

[37] G. Lee, K. Cho, Electronic structures of zigzag graphene nanoribbons with edge hydrogenation and oxidation, Phys. Rev. B, 79 (2009) 10.1103/PhysRevB.79.165440.

[38] Z.F. Huang, H.W. Bao, Y.Y. Yao, W.Y. Lu, W.X. Chen, Novel green activation processes and mechanism of peroxymonosulfate based on supported cobalt phthalocyanine catalyst, Appl. Catal. B, 154 (2014) 36-43. 
[39] C. Tan, N. Gao, Y. Deng, J. Deng, S. Zhou, J. Li, X. Xin, Radical induced degradation of acetaminophen with $\mathrm{Fe}_{3} \mathrm{O}_{4}$ magnetic nanoparticles as heterogeneous activator of peroxymonosulfate, J. Hazard. Mater., 276 (2014) 452-460. 